\title{
Catalytic use toward Redox Reaction of Toxic Industrial Wastes in Innocuous Aqueous medium and Antibacterial Activity of Novel $\mathrm{Cu}_{\mathrm{x}} \mathrm{Ag}_{\mathrm{x}} \mathrm{Zn}_{1-2 \mathrm{x}} \mathrm{O}$ Nanocomposites
}

\author{
Anik Sinha,, Sanjay Kumar Sahu, ${ }^{\dagger}$ Suman Biswas, ${ }^{\ddagger}$ Manab Mandal,": Vivekananda Mandal,": \\ Tanmay Kumar Ghorai ${ }^{+, *}$ \\ †Nanomaterials and Crystal Design Laboratory, Department of Chemistry, Indira Gandhi National Tribal \\ University, Amarkantak 484887, Madhya Pradesh, India \\ *Department of Chemistry, West Bengal State University, Barasat, Kolkata 700126, West Bengal, India \\ "Plant and Microbial Physiology and Biochemistry Laboratory, Department of Botany, University of Gour Banga, \\ Malda 732103, West Bengal, India
}

\section{Supporting Information File}

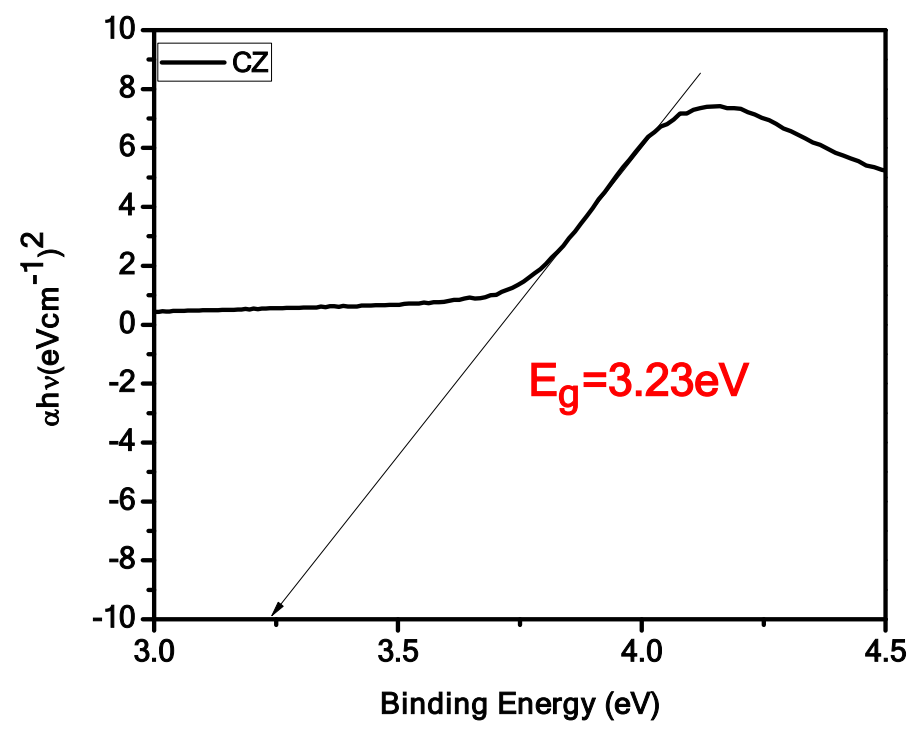

Figure S1: Band gap energy plot CZ 


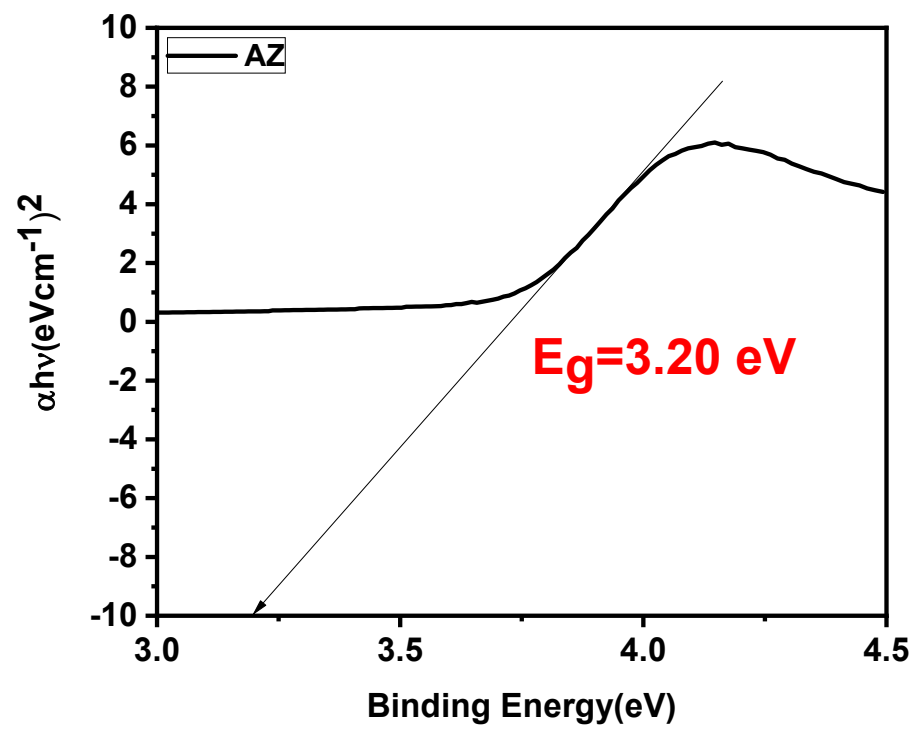

Figure S2: Band gap energy plot AZ

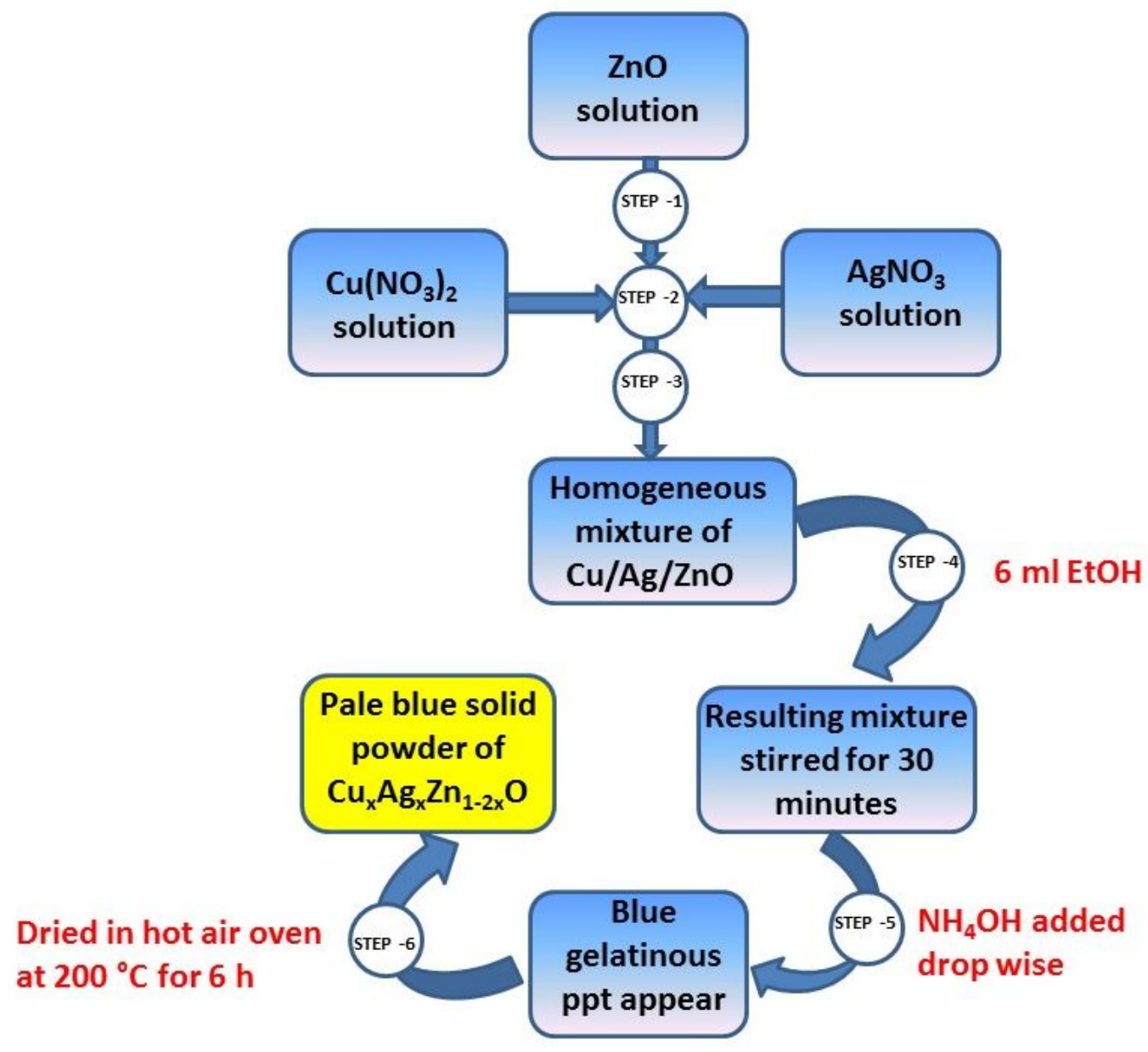


Figure S3: Flowchart diagram for synthesis of $\mathrm{Cu}_{\mathrm{x}} \mathrm{Ag}_{\mathrm{x}} \mathrm{Zn}_{1-2 \mathrm{x}} \mathrm{O}(\mathrm{x}=\mathbf{0 . 1})$

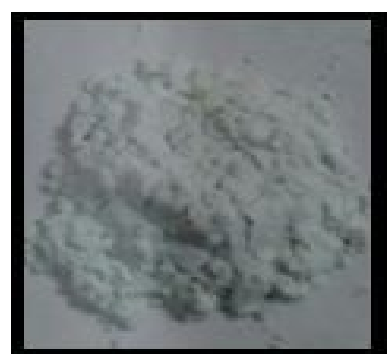

$\mathrm{Cu}_{\mathrm{x}} \operatorname{Ag}_{\mathrm{x}} \operatorname{Zn}_{1-2 \mathrm{x}} \mathrm{O}(\mathrm{x}=\mathbf{0 . 1})$

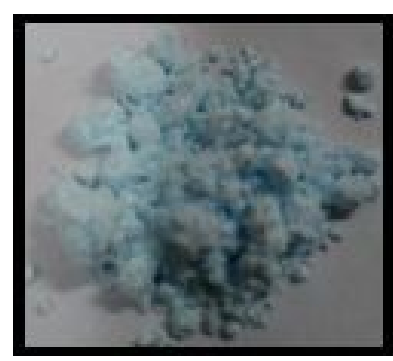

$\mathrm{Cu}_{\mathrm{x}} \mathrm{Zn}_{1-\mathrm{x}} \mathrm{O}(\mathrm{x}=\mathbf{0 . 1})$

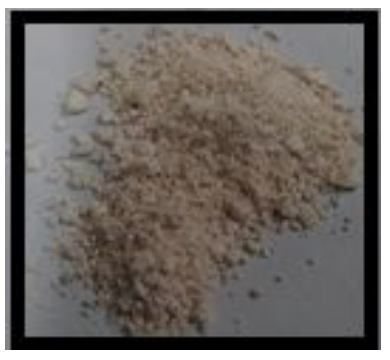

$\operatorname{Ag}_{x} Z_{n-x} O(x=0.1)$

Figure S4: Images of $\mathrm{Cu}_{\mathrm{x}} \mathrm{Ag}_{\mathrm{x}} \mathrm{Zn}_{1-2 \mathrm{x}} \mathrm{O}(\mathrm{x}=\mathbf{0 . 1})(\mathrm{CAZ}), \mathrm{Cu}_{\mathrm{x}} \mathrm{Zn}_{1-\mathrm{x}} \mathrm{O}(\mathrm{x}=0.1)(\mathrm{CZ})$, and $\mathrm{Ag}_{\mathrm{x}} \mathrm{Zn}_{1-\mathrm{x}} \mathrm{O}$ $(\mathrm{x}=\mathbf{0 . 1})(\mathrm{AZ})$ nanocomposite 